\title{
The Induction by Ultraviolet Radiation and the Photoreactivation of Heritable Respiratory Deficiency in Saccharomyces Adapted and Unadapted to Aerobic Respiration ${ }^{1}$
}

\author{
Alvin Sarachek \\ Department of Agronomy, Kansas State College, Manhattan, Kansas, U. S. A.
}

Received October 27,1957

Aerobic respiration in Saccharomyces is adaptive; the intact cytochrome chain and certain accessory enzymes are elaborated only under induction by molecular oxygen (Ephrussi and Slonimski 1950). Raut $(1953$; 1954) has demonstrated that yeast cells can be rendered genetically incapable of developing the terminal respiratory system through exposure to ultraviolet light. However, at least three considerations mark this induction of respiratory deficiency as atypical of radiation mutagenesis and suggest its possible origin in a heritable alteration of a system peculiary concerned with the adaptive formation of respiratory enzymes. First, unlike a typical mutational event, induced respiratory deficiency may occur in the majority of cells which survive ultraviolet irradiation. Moreover, the variant character is genetically ascribable to a disturbance to some extra-chromosomal agency which is maintained upon vegetative propagation but which cannot be transmitted through a sexual cross (Raut 1954). Second, the induction of respiratory deficiency is readily effected by ultraviolet radiation and not at all by $\mathrm{x}$-radiation (Raut and Simpson 1955). An analogous dissociation of the effects of ultraviolet and $\mathrm{x}$-radiations on the physiological inhibition of adaptive enzyme formation in Saccharomyces also has been noted (Swenson and Giese 1950; Barron et al. 1953). Third, respiration deficient variants which are genetically and physiologically identical to those produced by ultraviolet radiation may be induced by propagation of yeast cells in the presence of certain acridine dyes (Ephrussi et al. 1949). Significantly, only those dyes which exhibit the selective ability to disturb the adaptive formation of respiratory enzymes are effective as inducing agents (Slonimski 1953).

The present paper presents a study designed to evaluate the implied role of the adaptive enzyme forming mechanism in the loss of the terminal respiratory system through comparison of the susceptibilities of yeast cells, adapted and unadapted to aerobic respiration, to the induction by ultraviolet

1 This work was conducted with the aid of a research grant, RG 4561 ( $\mathrm{Cl}$ ), awarded to V. W. Woodward by the National Institutes of Health, Bethesda, Maryland, and was part of the thesis submitted to Kansas State College by Alvin Sarachek in partial fulfilment of the requirements for the degree of Doctor of Philosophy. Contribution No. 603, Department of Agronomy, Kansas Agricultural Experiment Station, Manhattan. 
radiation of heritable respiratory deficiency. Particular attention was given to assessing the relationship between cellular inactivation and the induction of respiratory deficiency, and to determining the influence of photoreactivation and post-irradiation respiratory conditions upon the expression of these radiation responses. The bearing of the results upon the nature of the genetic agency responsible for the transmission of respiratory capacity in Saccharomyces is discussed.

\section{Material and method}

The yeast stock. The yeast stock employed was a respiration competent, non-sporulating diploid strain of Saccharomyces which carried a homozygous deficiency for adenine synthesis, expressed phenotypically by the formation of a red pigment when cells were propagated aerobically on limiting amounts of adenine and an excess of glucose. It was derived through a somatic segregation induced by ultraviolet radiation (James and Lee-Whiting 1955) in the diploid stock 11294 of the Carbondale pedigree ${ }^{2}$ which was heterozygous for adenine deficiency. A single colony isolate of the adenineless variant was maintained on a 4 per cent glucose, 1 per cent yeast extract, nutrient agar at $5^{\circ} \mathrm{C}$ to serve as a stock inoculum throughout the course of the investigations. Respiratory variants of spontaneous origin occurred within this stock in a frequency of slightly over 2 per cent.

Media. Cells were cultivated for irradiation upon a synthetic broth of the following composition:

Glucose, $40 \mathrm{gm}$; asparagine, $2 \mathrm{gm}$; ammonium tartrate, $2 \mathrm{gm}$; $\mathrm{KH}_{2} \mathrm{PO}_{4}, 2 \mathrm{gm} ; \mathrm{K}_{2} \mathrm{HPO}_{4}, 0.3 \mathrm{gm} ; \mathrm{MgSO}_{4} \cdot 7 \mathrm{H}_{2} \mathrm{O}, 0.5 \mathrm{gm} ; \mathrm{CaCl}_{3}, 0.33$ gm; $\mathrm{FeSO}_{4} \cdot 7 \mathrm{H}_{2} \mathrm{O}, 3 \mathrm{mgm}$; $\mathrm{ZnSO}_{4} \cdot 7 \mathrm{H}_{2} \mathrm{O}, 3 \mathrm{mgm} ; \mathrm{CuSO}_{4} \cdot 5 \mathrm{H}_{2} \mathrm{O}, 0.5$ mgm; $\mathrm{MnSO}_{4} \cdot 4 \mathrm{H}_{2} \mathrm{O}, 0.4 \mathrm{mgm} ;\left(\mathrm{NH}_{4}\right)_{6} \mathrm{Mo}_{7} \mathrm{O}_{44} \cdot 4 \mathrm{H}_{2} \mathrm{O}, 0.15 \mathrm{mgm} ; \mathrm{Na}_{2} \mathrm{~B}_{4} \mathrm{O}_{7}$. $10 \mathrm{H}_{2} \mathrm{O}, 0.9 \mathrm{mgm}$; inositol, $10 \mathrm{mgm}$; thiamine hydrochloride, $1 \mathrm{mgm}$; pyridoxine, $0.6 \mathrm{mgm}$; nicotinic acid, $0.6 \mathrm{mgm}$; paraminobenzoic acid $0.6 \mathrm{mgm}$; calcium pantothenate $0.6 \mathrm{mgm}$; biotin, $0.01 \mathrm{mgm}$, adenine sulfate, $100 \mathrm{mgm}$; water, $1000 \mathrm{ml}$. The concentration of adenine sulfate indicated was beyond that necessary to provide a maximal growth rate. It was required, however, to insure complete suppression of the formation of red pigment by cells growing aerobically since cytoplasmic pigment depots, screening the nucleus from potentially effective radiation, could seriously influence the reliability of the experimental results.

The same medium was used for plating purposes following irradiation save for the reduction of adenine sulfate and glucose concentrations to $40 \mathrm{mg}$ and $20 \mathrm{gm}$ per liter respectively, and the addition of $20 \mathrm{mg}$ of $\mathrm{dl}$-methionine and $20 \mathrm{gm}$ of agar per liter. For some determinations the glucose of the plating 11294.

2 The author is indebted to Dr. Carl C. Lindegren for providing a culture of stock 
medium was replaced by an equivalent weight of certain organic acids and $\mathrm{pH}$ was readjusted to $6.2 \pm .2$ with $\mathrm{KOH}$.

Propagation of cells for irradiation. In Saccharomyces, the state of adaptation to aerobic respiration may be controlled by cultivating cells in the presence or absence of oxygen. To secure cells adapted to aerobic respiration, $100 \mathrm{ml}$ of broth, contained in a $500 \mathrm{ml}$ flask, were seeded with cells from the stock culture to a density of approximately $1 \times 10^{5}$ cells per $\mathrm{ml}$ and incubated at $28^{\circ} \mathrm{C}$ upon a reciprocal shaker operating at 115 three inch strokes per minute. After 48 hours incubation the cells were in a highly uniform interphase condition with less than 2 per cent of the individuals possessing buds. The enlarged vacuole and prominent mitochondria peculiar to yeast cells aerobically depleted of their carbohydrate reserves were evident (Sarachek and Townsend 1953). The necessity of using interphase cells exclusively in determining cellular susceptibility to radiations resides in the great diversity of responses to irradiation that a given strain may exhibit at various stages of the budding cycle (Sarachek 1954).

To cultivate cells anaerobically, screw cap test tubes, $20 \mathrm{~cm}$ by $2 \mathrm{~cm}$, filled to a depth of $18 \mathrm{~cm}$ with broth, were seeded with stock cells to a density of about $1 \times 10^{5}$ cells per $\mathrm{ml}$ and incubated without agitation at $28^{\circ} \mathrm{C}$. After six days the cells had ceased division and were in the desired interphase condition. Unlike aerobically cultivated cells, the anaerobically grown individuals exhibited small, frequently lobed vacuoles and minute mitochondria. Staining with saturated aqueous iodine solution also revealed the presence of massive vacuolar and cytoplasmic glycogen depots and confirmed the inability of the cells to carry out the aerobic dissimilation of their endogenous carbohydrate reserves (Stier and Stannard 1936).

Respirometry and nucleic acid analyses. The respiratory capacities of aerobically and anaerobically grown cells were compared by means of the Warburg apparatus. Measurements were made on 2 per cent glucose at $30^{\circ} \mathrm{C}$ by the indirect method of Warburg with air as the gas phase.

Inasmuch as both cellular inactivation and the induction of heritable respiratory deficiency by ultraviolet radiation appear to involve damage to nucleic acid components of the cell (Oster 1934; Raut and Simpson 1955), the deoxyribonucleic acid (DNA) and ribonucleic acid (RNA) contents of aerobically and anaerobically grown cells were compared. Determinations were made according to the method of Ogur and Rosen as adapted to the analysis of yeast (Ogur et al 1952)

Irradiation procedure. Cells were harvested from the growth medium by centrifugation, washed three times in $\mathrm{M} / 15 \mathrm{KH}_{\downarrow} \mathrm{PO}_{\star}$ and resuspended in $\mathrm{M} / 15 \mathrm{KH}_{-} \mathrm{PO}_{4}$ to a cell density of between $1 \times 10^{5}$ to $2 \times 10^{5}$ per $\mathrm{ml}$. Forty milliliters of the suspension were transferred to a sterile petri dish bottom, equipped with a magnetic stirrer, and irradiated at a distance of $37 \mathrm{~cm}$ from a 4 watt General Electric germicidal lamp delivering about 85 per cent of its 
over-all energy at wavelength $2537 \AA$. Measurements made by the Applied Engineering Division of the General Electric Company showed that energy at $2537 \AA$ incident upon the surface of the dish was delivered at the rate of 17 ergs per $\mathrm{mm}^{2}$ per second. A $1 \mathrm{ml}$ control sample was removed prior to irradiation and subsequent $1 \mathrm{ml}$ samples were removed after each interval of exposure and diluted in $\mathrm{M} / 15 \mathrm{KH}_{2} \mathrm{PO}_{4}$. The dilutions were such that $0.1 \mathrm{mI}$ spread upon the surface of a nutrient agar plate would introduce 50 to 200 cells capable of forming macroscopic colonies. Five plates were prepared for controls and for each interval of irradiation. In order to prevent photoreactivation all procedures were conducted in the presence of yellow light. The plates were incubated in the dark at $30^{\circ} \mathrm{C}$ for six days, at which time the percentage of surviving colony forming individuals as well as the proportion of mutants appearing among the survivors was determined.

Photoreactivation. To effect photoreactivation, $1 \mathrm{ml}$ samples were removed from the irradiated cell suspension and placed in $9 \mathrm{ml}$ of $\mathrm{M} / 15 \mathrm{KH}_{2} \mathrm{PO}_{4}$ contained in $2 \mathrm{~cm} \times 20 \mathrm{~cm}$ screw cap test tubes. The tubes were submerged to within an inch of the caps in a cylindrical pyrex water bath and illuminated for one hour by four 200 watt incandescent bulbs spotted equidistant about the circumference of the bath. To insure equal exposure of all tubes, the bath was rotated continuously during illumination. Because of the appreciable temperature coefficient of the photoreactivation process, particular care was taken to maintain the water bath temperature at $28^{\circ} \pm 2^{\circ} \mathrm{C}$ by occasional additions of ice. Following illumination, the cells were plated out and incubated as described above.

Technique for scoring respiratory variants. For purposes of population analyses, it has been customary to distinguish respiration deficient yeast cells by the fact that they form smaller colonies than normal cells under comparable growth conditions. However, since physiological disturbances unrelated to respiration may also result in a more or less protracted retardation of colonial development, recognition of the respiratory potential of colonies derived from irradiated cells must rely upon some characteristic which can be ascribed exclusively to cellular respiratory activity. The scoring technique adopted for the present study was based upon the observation that only the respiration sufficient cells of adenine requiring strains of Saccharomyces will form red pigment when cultivated on a medium containing glucose and adenine in appropriate concentrations (Tavlitzski 1951). With respect to color, it was observed that the colonies produced by irradiated cells were of the following types: 1) red, 2) white with over-growing red sectors, 3) white with red papillae, 4) $\tan$ to light orange and 5) white. The respiratory competencies of the cells comprising these colonies were assessed by restreaking representatives of each colony type upon glucose and upon lactate nutrient agar plates. The results indicated that all red colonies were composed of respiratory sufficient individuals. A lack of correspondence between 
colony size and respiratory capacity was confirmed by finding red colonies which, though scarcely larger than pin points, tested out as respiratory sufficient. The colonies exhibiting sectors or papillae consisted of mixtures of stable respiration sufficient and deficient cells, and presumably represented instances of respiratory deficient colonies in which a reversion to normal had occurred among one or more of the progeny of the original irradiated cell. Cells of the tan or orange colonies were qualitatively unique and gave evidence of having sustained a permanent instability in the expression and transmission of the aerobic respiratory mechanism. Though capable of limited growth when plated upon lactate, after several replatings on glucose agar they consistently threw some stable wild type individuals as well as five to twenty times the frequency of respiration deficient cells found spontaneously in the normal yeast colonies. All white colonies were comprised entirely of stable respiration deficient cells.

Thus, the character of colony pigmentation permitted a direct enumeration of both the stable and unstable respiratory variants induced by ultraviolet radiation. Screening of several hundred colonies established that, under the conditions of these experiments, the error in scoring variants which could be attributed to the criterion of colony pigmentation did not exceed two per cent (Sarachek 1957).

\section{Results}

Cellular inactivation. Ogur and St. John (1956) have proposed that a precise estimate of the proportion of respiratory variants within a population of normal cells may be secured through differential counts obtained by platings upon lactate and upon glucose agars; their suggestion was based upon the observation that lactate can be utilized only by respiration sufficient cells while glucose will support growth of both respiration sufficient and deficient cells. However, in preliminary experiments, when attempts were made to exploit the Ogur and St. John procedure to follow the course of induction of respiratory variants in ultraviolet irradiated populations, it was observed, contrary to expectations, that higher cell survival occurred upon the lactate than upon the glucose medium.

Survival curves of aerobically and anaerobically grown cells plated upon glucose and lactate with and without photoreactivation are depicted in Fig. 1. With reference to the curves obtained without photoreactivation, it is seen that cells cultivated anaerabically were more susceptible to inactivation than aerobically grown cells when the survival response was measured upon a medium containing glucose. The disparity in sensitivity was reflected in the amount of damage cells could withstand before inactivation and not in the final rate of logarithmic inactivation. In contrast, when glucose was replaced by lactate, this difference in sensitivity disappeared and the probabilities 
of both types of cell surviving irradiation were increased significantly. It may be inferred from this that the survival responses obtained upon glucose reflected differences in the ability of cells to repair radiation damage rather than

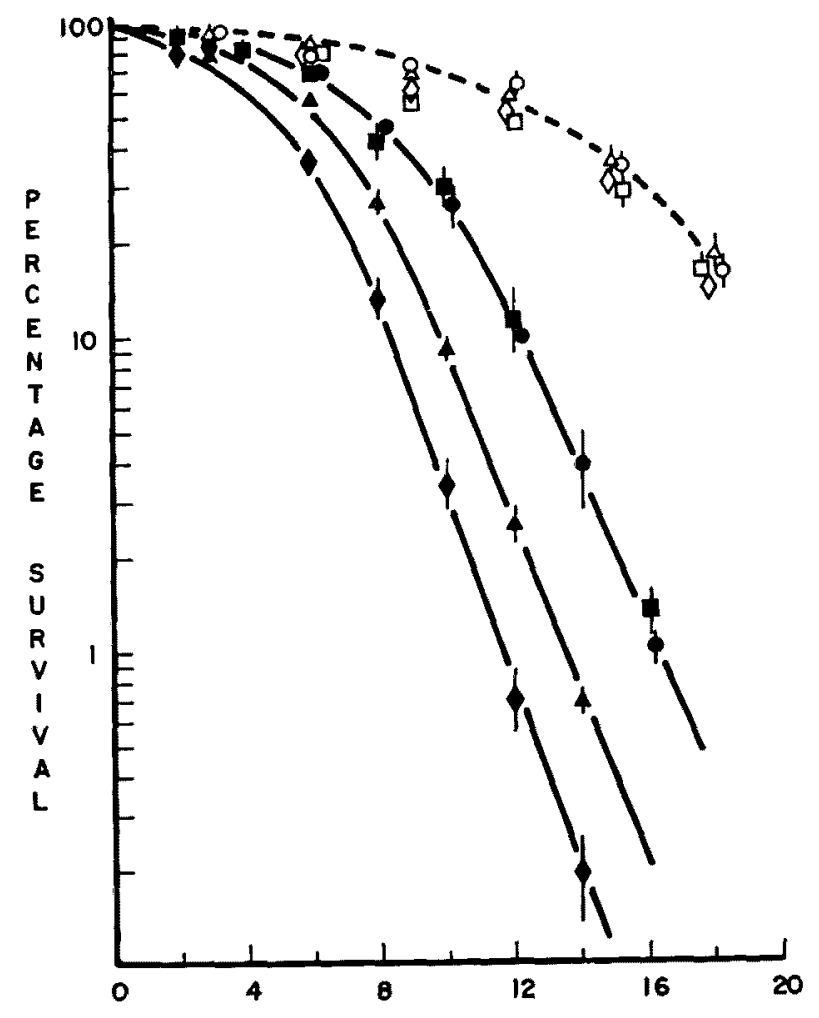

ULTRAVIOLET DOSAgE IN MINUTES OF EXPOSURE

Fig. 1. Ultraviolet inactivation curves of cells plated upon glucose or lactate medium. Diamonds represent anaerobically grown cells plated upon glucose; triangles represent aerobically grown cells plated upon glucose; squares represent anaerobically grown cells plated upon lactate; circles represent aerobically grown cells plated upon lactate. Closed and open symbols indicate before and after photoreactivation respectively. Values are means \pm one standard error based upon 5 determinations for non-photoreactivated cells and 3 determinations for photoreactivated cells. differences in the total amount of damage they sustained.

Anaerobically

grown cells differed from those grown aerobically in their higher RNA content and much lower oxidative respiratory activity (Table 1 ). It seems unlikely that the dissimilarity in RNA contents could account for the survival responses on glucose since it would be expected to condition primarily the amount of energy absorbed. Futhermore, there would be no reason to suspect that any post-irradiation physiological influence that the RNA concentration might exert would not be expressed equally well upon actate as upon glucose. The observation that marked differences in amount of cellular

RNA neither enhanced nor depressed cellular inactivation suggested that the RNA content of aerobically grown cells exceeded a threshold for effecting a detectable influence upon the radiation response.

On the other hand, a plausible relation between the survival responses and the cellular respiratory activities after irradiation could be shown. Upon glucose, anaerobically grown cells respired solely through a vigorous aerobic fermentation until they adapted to the ability to respire oxidatively (Table 1; Slonimski 1953). Aerobically grown cells also carried on an aerobic fer- 
mentation, but in addition had some immediate capacity for oxidizing glucose. When plated upon lactate, both types of cell could grow only by oxidative utilization of the substrate; aerobic cells could do so immediately while

Table 1. Nucleic acid contents and respiration of aerobically or anaerobically grown yeast cells*

\begin{tabular}{lrcccc}
$\begin{array}{c}\text { Cultural } \\
\text { condition }\end{array}$ & $\begin{array}{c}\text { Nucleic acid contents } \\
\text { expressed in micrograms } \\
\text { per } 10^{9} \text { cells }\end{array}$ & \multicolumn{2}{c}{ Respiratory Activity } \\
& RNA & DNA & $\mathrm{QO}_{2}$ & $\mathrm{QCO}_{2}$ & $\mathrm{QO}_{2}$ endogenous \\
\hline Aerobic & $864 \pm 47$ & $50.4 \pm 3.0$ & $52 \pm 3.4$ & $138 \pm 13$ & $<5$ \\
Anaerobic & $2857 \pm 131$ & $51.7 \pm 5.2$ & ca. 0 & $295 \pm 15$ & 0
\end{tabular}

* Values indicated are means \pm one standard error based upon 4 determinations on aerobically grown cells and 3 determinations on anaerobically grown cells.

anaerobic cells were required to adapt to this utilization. Since anaerobically grown cells did survive upon lactate, it is possible that they possessed some residual trace of the terminal respiratory mechanism which, though undetectable manometrically (Table 1), sufficed to enable them to carry out the oxidative mobilization of their endogenous reserves to provide energy for the complete adaptation (Stier and Stannard 1936). Thus, in agreement with their survival responses, the respiratory activities of aerobically and anaerobically grown cells differed qualitatively upon glucose but became equivalent upon lactate. The greater the cell's reliance upon aerobic respiration following irradiation, the greater was the probability of its repairing radiation damage.

In order to establish whether the correspondence between cellular respiration and radiation responses reflected a truly causal relationship, survival determinations were made of irradiated, aerobically grown cells, plated upon glucose medium and incubated in the absence of oxygen. Conditions for anaerobic incubation were created by placing the plates in a vacuum dessicator which then was evacuated to a pressure of about $20 \mathrm{~mm}$ of mercury and refilled with oxygen free nitrogen three successive times. Survival curves obtained under these conditions were equivalent to those of anaerobic cells incubated aerobically, thereby substantiating the inference that post-irradiation respiratory activity conditions the probability of cell survival. Furthermore, it was determined that the first twenty-four hours of incubation following irradiation was the critical period during which the quality of cellular respiration could exert an influence on the survival response. The failure of protracted anaerobic incubation to enhance the inactivational response is best explained by the fact that, even under aeration, yeast cells growing upon glucose rely almost entirely upon their anaerobic respiration. (Ephrussi et al 1956). Unfortunately, it was not possible to ascertain the survival responses of respiration deficient variants relative to those of aerobically or anaerobically grown respiration sufficient cells since, under the conditions of 
the experiments, the variants could not be obtained in a non-budding condition suitable for such comparisons. However, the report by Pittman (1957) that respiration deficient variants of a tetraploid strain of Saccharomyces exhibit appreciably greater susceptibility to inactivation by ultraviolet radiation than do the aerobically grown respiration sufficient cells from which they were derived, agrees with the present findings and their interpretation.

After photoreactivation (Fig. 1), the survivals obtained upon glucose and upon lactate for aerobically and anaerobically grown cells were the same. From this it may be concluded that (a) the physiological processes involved in the repair of inactivational damage during illumination with visible light do not require aerobic respiration and that (b) a segment of the damage expressed on glucose but repaired by the oxidative respiration on lactate is reparable alternatively by visible light.

Induction of respiration deficient variants. Respiratory variants of spontaneous origin were found in aerobic and anaerobic cultures in mean frequencies of $2.74( \pm 0.29 \mathrm{~S} . \mathrm{E}, 5$ determinations $)$ and $2.06( \pm 0.26 \mathrm{~S}$. E., 5 determinations) per 100 cells respectively. Statistically, the difference between these means was not significant $(t=1.214,8 \mathrm{D} / \mathrm{F}, P>.2)$. This finding accords with the prior demonstration by Harris (1956) that aerobiosis is not a selective factor in maintaining the population equilibrium between the respiration deficient and sufficient cells in yeast cultures. It is not readily reconciled, however, with the claim of Lindegren and Hino (1957) that anaerobiosis effects an extensive transformation of normal cells into respiration deficient variants.

All colonies derived from spontaneous variants were stable while those arising from induced cells were either stable or unstable. In Fig. 2 the ultraviolet dose-response curves defining the induction of respiratory deficiency in aerobically and anaerobically grown cells are presented; the frequencies of stable variants alone are plotted independently of the frequencies of stable and unstable variants. At low doses of radiation, the frequencies of total variants increase in a simple logarithmic fashion while those for stable variants increase in a more complex way. These relationships resembled those uncovered by Demerec and Latarjet (1946) for the induction by ultraviolet radiation of end point and zero point gene mutations in Escherichia coli. The total variants correspond to the end point mutants in their logarithmic rate of increase at low doses and the fact that, in some cases, their genetic fate is not determined until a number of cell divisions succeeding irradiation; the stable variants correspond to zero point mutants in that their rate of induction is more than logarithmic and the genetic fate of their descendents is decided prior to their first division following irradiation. It is particularly interesting to note that the spontaneous variant frequencies fell upon the logarithmic curves of induced total variant frequencies, suggesting that the induced variants arise through the same 
physiological disturbances responsible for the production of spontaneous variants.

Cross reference to Figs. 1 and 2 would suggest a possible interrelation

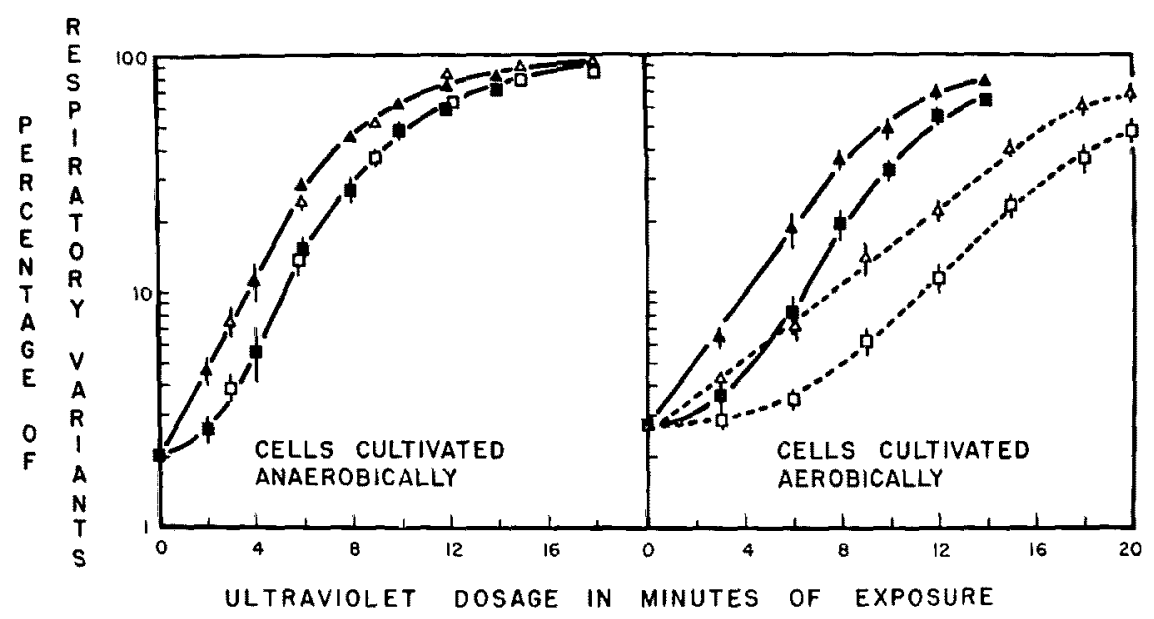

Fig. 2. Ultraviolet dose-response curves for the induction of respiratory deficiency in aerobically grown and anaerobically grown cells. Squares represent stable variants; triangles total, stable plus unstable, variants. Closed and open symbols indicate before and after photoreactivation respectively. Values given are means \pm one standard error based upon 5 determinations upon non-photoreactivated cells and three determinations upon photoreactivated cells.

between induced respiratory deficiency and cellular inactivation inasmuch as the rates of induction of both stable and unstable variants fell off at those dosages which market the onset of logarithmic inactivation. Also, as was observed for inactivation, cells unadapted to respiration were much more susceptible to the induction of respiratory deficiency than adapted cells. The logarithmic rates of induction of total variants as determined by a least squares fit of the experimental points were $0.140( \pm 0.004 \mathrm{~S}$. E.) and 0.189 $( \pm 0.003 \mathrm{~S} . \mathrm{E}$.) for aerobic and anaerobic cells respectively. The difference between these values tested out as highly significant $(t=9.25,4 \mathrm{D} / \mathrm{F}, P<$ .001). On the other hand, while inactivational damage to both aerobically and anaerobically grown cells was readily repaired by exposure to visible light, induced respiratory deficiency could be photo-repaired only in respiration adapted cells. Unless the unlikely assumption is made that fundamentally different biochemical processes underly the photoreactivation of the variously expressed forms of cellular disturbances effected by ultraviolet irradiation, it must be concluded that the site of damage resulting in inactivation is not identical to that responsible for the maintenance of cellular respiratory compentence. Since abundant evidence exists to indicate that only that radiation damage sustained within the cell nucleus is capable of photoreactivation (Kelner, 1953; Brandt and Giese 1956), it appeared that cellular inactivation and induced respiratory deficiency resulted from different events which were 
related to the extent that they were both nuclear.

Unlike the response to photoreactivation, the differential susceptibilities of anaerobically and aerobically grown cells to the induction of respiratory deficiency reflected a dependence upon post-irradiation respiratory activity rather than the state of cellular adaptation to respiration per se. By imposing anaerobic conditions immediately following irradiation, it was possible to effect an appreciable increase in the rate of logarithmic induction of total respiratory variants in aerobically grown cells. Pooling the results of three

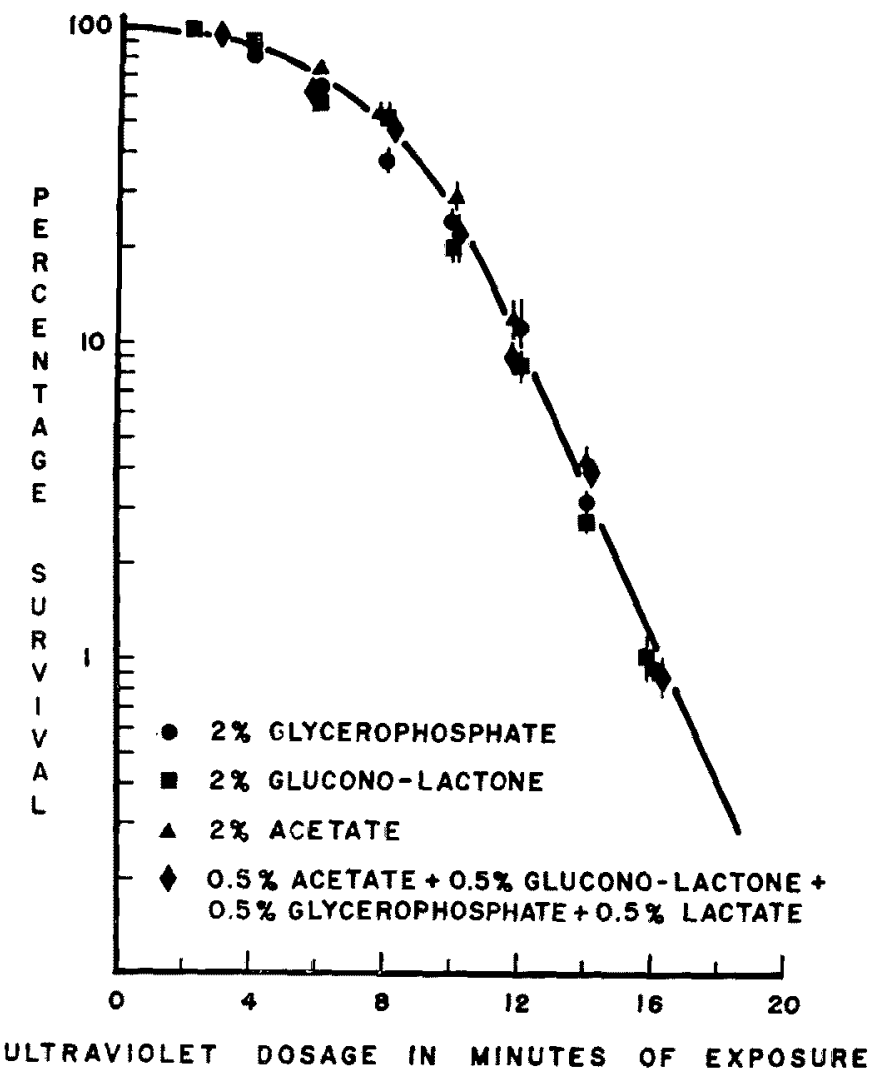

Fig. 3. Ultraviolet inactivation data for aerobically grown cells plated upon aerobically utilized carbon substrates. The curve drawn is the same depicted in Fig. 1 for aerobic cells plated upon lactate. Each value shown is the mean of three determinations \pm one standard error. experiments showed that twenty-four hours of anaerobiosis raised the induction rate from 0.140 ( \pm 0.004 S. E.) to $0.168( \pm 0.004 \mathrm{~S}$. E.); the increase was statistically significant at the .01 per cent level ( $t=3.66,4$ d.f., $.01>P>.005)$. The survival responses of irradiated cells plated upon glucose and lactate media illustrated the full extent of this dependence. Because lactate is a proven selective substrate for respiration sufficient cells, the fact that a greater number of cells survived ultraviolet irradiation when plated upon lactate than upon glucose implied either that (1) the true cell survival upon lactate should be higher than that observed by a factor corresponding to the frequency of variants induced or that (2) lactate exerted a reparative action upon irradiated cells while they were in a pre mutational state. The first alternative was discounted by the survival responses of aerobically and anaerobically grown cells after photoreactivation. Induced respiratory deficiency was not photoreversible in anaerobically grown cells. Therefore, if lactate did not modify the genetic destinies of the cells but simply selected against 
respiratory variants, it would be expected that the survival of irradiated anaerobically grown cells upon lactate after photoreactivation would be far less than that of aerobically grown cells. That the survivals were identical supported the proposition that the mechanism responsible for the genetic maintenance of the terminal respiratory system was rendered liable to loss through irradiation but was completely stabilized or conserved when cells respired only aerobically. Accordingly, an observation by Raut (1954) that irradiated yeast cells will not develop heritable respiratory deficiencies if

Table 2. The influence of glucose concentrations in the plating medium upon cell survival and the proportion of respiratory variants induced in aerobically grown cells after 10 minutes irradiation

\begin{tabular}{|c|c|c|c|c|c|c|c|}
\hline \multicolumn{8}{|c|}{ Glucose concentration in per cent } \\
\hline \multicolumn{2}{|c|}{0.2} & \multicolumn{2}{|c|}{0.5} & \multicolumn{2}{|c|}{2.0} & \multicolumn{2}{|c|}{8.0} \\
\hline$S^{*}$ & $V^{* *}$ & $S$ & $V$ & $s$ & $V$ & $S$ & $V$ \\
\hline 107 & 27 & 109 & 34 & 98 & 22 & 116 & 36 \\
\hline 101 & 19 & 103 & 41 & 97 & 34 & 115 & 29 \\
\hline 98 & 11 & 101 & 37 & 96 & 29 & 105 & 42 \\
\hline 98 & 28 & 96 & 30 & 93 & 29 & 103 & 28 \\
\hline 96 & 26 & 95 & 18 & 93 & 19 & 99 & 30 \\
\hline 94 & 32 & 95 & 34 & 91 & 20 & 99 & 23 \\
\hline 91 & 16 & 93 & 19 & 87 & 20 & 94 & 26 \\
\hline 90 & 10 & 88 & 35 & 86 & 22 & 93 & 18 \\
\hline 80 & 19 & 84 & 20 & 84 & 19 & 88 & 24 \\
\hline 79 & 24 & 84 & 23 & 83 & 18 & 85 & 25 \\
\hline
\end{tabular}

Analyses of Variance

A Survival

\begin{tabular}{lccc} 
Source of variation & $\begin{array}{c}\text { Sum of } \\
\text { squares }\end{array}$ & $\begin{array}{c}\text { Degree of } \\
\text { freedom }\end{array}$ & $\begin{array}{c}\text { Mean } \\
\text { square }\end{array}$ \\
\hline Treatments & 412.2 & 3 & 134.1 \\
Error & 2504 & 36 & 69.56 \\
& $F=1.93$ & $P>.1$ &
\end{tabular}

$B$ Respiratory variants

\begin{tabular}{lccc} 
Source of variation & $\begin{array}{c}\text { Sum of } \\
\text { squares }\end{array}$ & $\begin{array}{c}\text { Degree of } \\
\text { freedom }\end{array}$ & $\begin{array}{c}\text { Mean } \\
\text { square }\end{array}$ \\
\hline Treatments & 435.0 & 3 & 145 \\
Error & 1916 & 36 & 53.3
\end{tabular}

$F=2.72 \quad P>.1$

* total colonies per plate

** respiration deficient colonies per plate

plated upon a natural medium devoid of sugar can be related to their absolute dependence for growth, under such conditions, upon the oxidative dissimilation of nitrogenous organic compounds. 
The relative significance of fermentation and aerobic respiration to the radiation responses. The differential responses of irradiated yeast cells on lactate and glucose media indicated either that glycolysis potentiated the effect of irradiation or that aerobic respiration increased the ability of the yeast cell to repair radiation damage. In order to discriminate between these alternatives experiments were conducted upon aerobically grown cells under conditions which would vary the quantitative relationship of glycolysis to oxidative respiration following irradiation.

It is known that higher glucose concentrations in the growth medium favor an increase of aerobic fermentation relative to aerobic respiration (Ephrussi et al 1956). Cells, irradiated for 10 minutes, were plated upon media containing glucose in various concentrations. After five days incubation the numbers of colonies surviving were determined and the glucose

Table 3. The influence of mixtures of glucose $(G)$ and acetate (A) or a-glycerphosphate $(T)$ in the plating medium upon cell survival and the proportion of respiratory variants induced in aerobically grown cells after 10 minutes irradiation

\begin{tabular}{|c|c|c|c|c|c|c|c|c|c|c|c|}
\hline \multicolumn{12}{|c|}{ Concentration of carbon substrates in per cent } \\
\hline \multicolumn{2}{|c|}{$2(G)$} & \multicolumn{2}{|c|}{$2(\mathrm{~A})$} & \multicolumn{2}{|c|}{$0.5(\mathrm{G}) / 1.5(\mathrm{~A})$} & \multicolumn{2}{|c|}{$1.0(\mathrm{G}) / 1.0(\mathrm{~A})$} & \multicolumn{2}{|c|}{$0.5(\mathrm{G}) / 1.5(\mathrm{~T})$} & \multicolumn{2}{|c|}{$1.0(\mathrm{G}) / 1.0(\mathrm{~T}$} \\
\hline$N^{*}$ & $V * *$ & $N$ & $V$ & $N$ & $V$ & $N$ & $V$ & $N$ & $V$ & $N$ & $V$ \\
\hline 79 & 22 & 206 & - & 85 & 13 & 86 & 17 & 85 & 14 & 93 & 12 \\
\hline 79 & 12 & 201 & - & 85 & 10 & 84 & 11 & 83 & 19 & 90 & 7 \\
\hline 74 & 19 & 194 & - & 70 & 7 & 75 & 12 & 77 & 15 & 84 & 14 \\
\hline 70 & 9 & 192 & - & 70 & 17 & 73 & 7 & 76 & 14 & 81 & 21 \\
\hline 63 & 13 & 187 & - & 67 & 9 & 71 & 8 & 70 & 18 & 79 & 10 \\
\hline 61 & 20 & 183 & - & 62 & 12 & 67 & 10 & 63 & 9 & 73 & 12 \\
\hline
\end{tabular}

Analyses of variance

A Survival***

\begin{tabular}{lccc} 
Source of variation & $\begin{array}{c}\text { Sum of } \\
\text { squares }\end{array}$ & $\begin{array}{c}\text { Degree of } \\
\text { freedom }\end{array}$ & $\begin{array}{c}\text { Mean } \\
\text { square }\end{array}$ \\
\hline Treatments & 520.7 & 4 & 130.2 \\
Error & 1651 & 25 & 66.4 \\
& $F=1.97$ & $P>.1$ &
\end{tabular}

$B$ Respiratory variants

\begin{tabular}{lccc} 
Source of variation & $\begin{array}{c}\text { Sum of } \\
\text { vquares }\end{array}$ & $\begin{array}{c}\text { Degree of } \\
\text { freedom }\end{array}$ & $\begin{array}{c}\text { Mean } \\
\text { square }\end{array}$ \\
\hline Treatments & 114 & 4 & 28.5 \\
Error & $\begin{array}{l}434 \\
\text { F }\end{array}$ & 25 & 17.4 \\
& $P>.1$ & &
\end{tabular}

* total colonies per plate

** respiration deficient colonies per plate

*** survival values upon acetate alone (2A) were obviously significantly higher than the others and, therefore, were excluded from the analysis of variance.

plates were replicated to lactate agar to determine the number of induced stable respiratory variants. It was necessary to resort to the replicate plating device and, thereby, to restrict analysis to survival and stable variants, since 
alteration of the ratio of glucose to adenine in the plating medium obscured the pigmentation characteristics distinguishing colonies of respiration sufficient and deficient cells. The results of these determinations are given in Table 2. Analyses of variance failed to detect a significant influence of glucose concentrations upon either survival or variant induction.

To test the importance of the equality of respiration further, survival determinations were made of irradiated cells plated on $\alpha$-glycerophosphate, glucono-lactone and acetate either individually or all in combination with lactate. Though, like lactate, these carbon substrates can be utilized by yeasts only aerobically, glucono-lactone and $\alpha$-glycerophosphate enter into the glycolytic pathway while acetate does not. From Fig. 2 it can be seen that, on each of three substrates, irradiated cells gave the same survival as on lactate. Furthermore, since mixtures of the substrates supported the same response as each of the substrates individually, it could be assumed that they all effected the high level of survival through some common characteristic. Therefore, it appeared unlikely that the response of lactate resulted simply from circumventing glycolysis, and more probable that it reflected the preservation of some system damaged by irradiation through the necessary operation of the terminal hydrogen transport mechanism during growth.

The extent of survival and development of respiratory deficiency by irradiated cells plated upon mixtures of glucose with acetate or $\alpha$-glycerophosphate were assessed by a replicate plating experiment similar to the one described above. The results shown in Table 3 revealed that glucose reversed the reparative influence of the aerobic substrates and suggested that repair required the exclusive occurrence of aerobic respiration following irradiation.

\section{Discussion}

The probability of occurrence of cellular inactivation or heritable loss of respiratory capacity in ultraviolet irradiated yeast cells was determined by the nature of the postirradiation respiratory activity and not the level of cellular adaptation to respiration prior to irradiation. When post-irradiation growth conditions were such that cells effected an appreciable aerobic fermentation (i. e. cells plated upon glucose), respiratory deficiencies developed and the probability of inactivation was high; when conditions were provided which would permit growth only through aerobic respiration, (i.e. cells plated on lactate), no respiratory deficiency developed and the probability of cellular inactivation decreased significantly. Varying the quantitative relationship of fermentative to oxidative respiration in irradiated cells established that these differences in responses were not attributable to a debilitating effect of fermentation but reflected a stabilizing influence of the mandatory operation of the terminal respiratory mechanism. The basis of the repara. ive influence of aerobic respiration upon inactivational damage is unclear, 
particularly in view of the fact that for E. coli, which like Saccharomyces is a faculative anaerobe, the operation of the terminal respiratory mechanism accentuates the susceptibility to inactivation by both ionizing (Hollaender et al. 1951) and non-ionizing radiations (Mefferd and Matney 1952). On the other hand, its bearing upon the induction of heritable respiratory deficiency is readily explicable on the assumption that irradiation retards the replication of the specific genetic determinant (s) responsible for the maintenance of the aerobic respiratory mechanism to a greater extent than that of determinants directing other essential cellular syntheses. Thus, growth proceeding largely at the expense of fermentation would be conducive to loss of the superfluous respiratory determinant (s) while growth attuned to the obligatory operation of the terminal respiratory mechanism would exert positive selection for the determinant's retention.

Even though the expression of radiation damage effecting respiratory deficiency was controlled by the natural post-irradiation cellular respiration, photoreactivation studies showed that the site of damage was associated with the system for the adaptive formation of respiratory enzymes. Photoreactivation of induced respiratory deficiency occurred only in cells which were adapted to aerobic respiration prior to irradiation; inactivational injury was photo-reparable in both adapted and unadapted cells. As it is highly probable that common biochemical processes underlie all photoreactivation phenomena, the absence of photoreactivation of induced respiratory deficiency in unadapted cells cannot be attributed to a necessary involvement of respiration in the repair process, but rather can be taken to imply that the sites of induction existed in different functional states in cells adapted and unadapted to respiration. Since the reparative action of visible light is restricted to ultraviolet damage inflicted within the cell nucleus both induced respiratory deficiency and cellular inactivation appeared to result from nuclear disturbances. That those disturbances were not identical, however, was evidenced by the dissimilarities in photo-reversal of the two responses which were dependent upon the cellular state of adaptation to respiration.

The pattern of inheritance of respiratory deficiency in Saccharomyces, has been generally assumed to indicate that the extra-chromosomal determinant ( $\mathrm{s}$ ) of cellular respiratory capacity resides within the cytoplasm (Ephrussi 1953, Lindegren 1956). However, sexual reproduction in Saccharomyces is isogamous and, consequently, the interpretation of cytoplasmic inheritance is merely a tentative explanatory hypothesis which cannot be validated by genetic means alone. The correct assignment of the heritable respiratory determinant (s) to the nucleoplasm or cytoplasm must rely upon the correlation of induction or repair of respiratory deficiency by chemical or physical treatments with the specific cellular loci at which such treatments express their activity. In the present study, the photoreactivation data ostensibly dispute the cytoplasmic nature of the respiratory determinant 
(s). Still, unless the induction of respiratory deficiency is due to the direct inactivation of the determinant (s), the nuclear nature of the inducing damage need not be relevant to the intracellular location of the determinant itself. The capacity of the yeast cell for maintaining the extra-chromosomal determinant (s) is known to be governed by some activity of the nucleus (Chen et al 1950, Ephrussi and Hottinguer, 1952). The nuclear nature of the inducting event may only reflect interference with some regulatory nuclear function and need not contradict the putative cytoplasmic character of the respiratory determinant (s). Consequently these studies have demonstrated with certainty only that the induction of heritable respiratory deficiency by ultraviolet radiation results from damage to a nuclear entity involved in the adaptive formation of respiratory enzymes. While they cannot permit a conclusive definition of the extra-chromosomal respiratory determinant (s), they do serve a potentially significant purpose in casting some doubt upon the validity of the cytoplasmic inheritance of respiration in Saccharomyces.

\section{Summary}

That ultraviolet-induced respiratory deficiency in Saccharomyces was photoreversible implicated the nucleus as the site of radiation damage; further, the fact that only the induction of variants in respiration adapted cells was photoreversible supported the primary conclusion drawn from this work that the induction of respiration deficiency resulted from damage to a nuclear entity involved in the adaptive formation of respiratory enzymes. Unlike the photoreactivation of induced respiration deficient variants, photoreactivation of inactivational damage was independent of the state of cellular adaptation to respiration. This, together with the observation that the expression of ultraviolet damage resulting in the production of respiration deficient variants was completely determined by post-irradiation respiratory conditions while the expression of inactivational damage was only partly so determined, revealed that cellular inactivation and the induction of respiratory variants involve different nuclear disturbances.

This paper presents the first experimental challenge to the hitherto accepted concept that non-segregational, respiratory deficiency in Saccharomyces is cytoplasmically inherited.

\section{Literature cited}

Barron, L. S., S. Spiegelman and Quastler, H. 1953. Enzyme formation in non-viable cells. Jour. Gen. Physiol. 36: 631.

Brandt, C. L. and Giese, A. C. 1956. Photoreversal of nuclear and cytoplasmic effects of short ultraviolet radiation on Paramiceum candatum. Jour. Gen. Physiol. 39: 735.

Chen, S., Ephrussi, B. and Hottinguer, H. 1950. Nature genetique des mutants a deficience respiratoire de la sauche B-11 de la levure de boulangerie. Heredity 4: 337.

Demerec, M. and Laterjet, R. 1946. Mutants in bacteria induced by radiation. Cold Spring Harb. Symp. Quant. Biol. 10: 38. 
Ephrussi, B. 1953. Nucleo-cytoplasmic Relations in Micro-organisms. Oxford: Clareudon Press.

- and Slonimski, P. P. 1950. La synthese adaptative des cytochromes chez la levure de boulaugerie. Biochnm. Biophy. Acta 6: 256.

- and Hottinguer, H. 1951. On an unstable state in yeast. Cold Spring Harb. Symp. Quant. Biol. 16: 75.

- Hottinguer, H. and A. Chimenes 1949. Action de l'acriflavin sur les levures. 1. La mutation petite colonie. Ann. Inst. Pasteur. 76: 351.

- Slonimski, P. P., Yotsuyanagi, Y. and Tavlitzski, J. 1956. Variations physiologiques et cytologiques de la levure au cours du cycle de la croissan e aerobie. Comp. rend. Lab. Carlsberg, Ser. physiol. 26: 87.

Harris, M. 1956. Occurrence of respiration deficient mutants in bakers yeast cultivated anaerobically. Jour. Cell and Comp. Physiol. 48: 95.

Hollaender, A., Stapleton, G. E. and Burnett, W. T. 1951. X-ray sensitivity of $E$. coli as modified by oxygen tension. Nature 167: 103.

James, A. P. and Lee-Whiting, B. 1955. Radiation induced genetic segregations in vegetative cells of diploid yeast. Genetics 40: 826.

Kelner, A. 1953. Growth, respiration and nucleic acid synthesis in ultraviolet irradiated and photoreactivated Escherichia coli. Jour. Bacteriol. 65: 252.

Lindegren, C. C. 1956. Mutation and other variations in microorganisms. Compt. rend. Lab. Carlsberg, Ser. physiol. 26: 253.

- and Hino, S. 1957. The effect of anaerobiosis on the origin of respiration-deficient. yeasts. Expt. Cell Res. 12: 163.

Mefferd, R. B. and Matney, T. S. 1952. Protection of Escherichia coli against uItraviolet radiation by pretreatment with carbon monoxide. Science 115,116 .

Ogur, M., S. Minckler, G. Lindegren and C. C. Lindegren 1952. Nucleic acids in a polyploid series of Saccharomyces. Arch. Biochem. and Biophys. 40: 175.

- and R. St. John, 1956. A differential and diagnostic plating method for population studies of respiration deficiencies in yeast. Jour. Bacteriol. 72:500.

Oster, R. H. 1934. Results of irradiating Saccharomyces with monochromatic ultraviolet light 1II. The absorption of ultraviolet energy by yeast. Jour. Gen. Physiol. 18: 251.

Pittman, D. D. 1957. Induction of respiratory deficiency in tetraploid Saccharomyces by ultraviolet radiation. Expt1. Cell. Res. 11: 654.

Raut, C. 1953. A cytochrome deficient mutant of Saccharomyces cerevisiae. Exptl. Cell. Res. 4: 295.

- 1954. Heritable non-genic changes induced in yeast by ultraviolet light. Jour. Cell. and Comp. Physiol. 44: 463.

- and Simpson, W. L. 1955. The effect of X-rays and ultraviolet light of different wave lengths on the production of cytochrome deficient yeasts. Arch. Biochem. and Biophys. 57: 218.

Sarachek, A. 1954. Ultraviolet inactivation of Saccharomyces during the budding cycle Exptl. Cell. Res. 6: 45.

- 1957. Doctoral dissertation, Kansas State College, 1957.

- and Townsend, G. F. 1953. Disruption of the mitochondria of Saccharomyces by ultraviolet irradiation. Science 117: 31.

Slonimski, P. P. 1953. A specific relation between enzymic adaptation and cytoplasmic mutation in Adaptation in. Micro organisms. London: Cambridge Press.

Stier, T. J. B., and Stannard, J. N. 1936. The metabolic system involved in dissimilation of carbohydrate reserves in bakers yeast. Jour. Gen. Physiol. 19: 479.

Tavlitzski, J. 1951. Conditions of pigment formation in a red yeast. Rev. Can. biol. 10: 48. 